\title{
$\mathrm{COSCi}^{-}$ech Jurnal Computer Science and Information Technology (CoSciTech)
}

\section{Evaluasi usabilitas website e-learning umri terhadap mahasiswa umri menggunakan metode usability testing}

Evans Fuad $^{* 1}$, Regiolina Hayami ${ }^{2}$, Almer Kharisma ${ }^{3}$

Email: ${ }^{1}$ evansfuad@umri.ac.id, ${ }^{2}$ regiolinahayami@umri.ac.id, ${ }^{2} 170401026 @$ student.umri.ac.id

${ }^{123}$ Teknik Informatika, Fakultas Ilmu Komputer, Universitas Muhammadiyah Riau

Diterima: 10 Oktober 2021 | Direvisi: - | Disetujui: 20 Desember 2021

C2021 Program Studi Teknik Informatika Fakultas Ilmu Komputer

Universitas Muhammadiyah Riau, Indonesia

\begin{abstract}
Abstrak
Analisa usabilitas website dapat membantu memberikan evaluasi pengembangan website. Melalui analisa usabilitas dapat membantu meningkatkan terhadap penggunaan sistem. Begitu juga pada website $e$-learning UMRI, analisa usabilitas dapat memberikan masukan bagi pengembang website SIKULI UMRI. Adanya keluhan dari mahasiswa tidak dapat mengirim tugas dengan jumlah file yang banyak dan pernah terjadinya pesan pada kolom diskusi yang terkirim secara berulang. Dalam hal ini analisa usabilitas bertujuan agar website SIKULI UMRI dapat lebih baik saat digunakan oleh mahasiswa UMRI. Dalam penelitian ini menggunakan metode Usability Testing dengan menggunakan 5 variabel. Penelitian dilakukan dengan mengumpulkan data menggunakan kuesioner online disebarkan kepada 99 mahasiswa UMRI. Pengolahan data kuesioner menggunakan aplikasi Minitab. Penelitian ini menemukan bahwa website SIKULI UMRI memiliki nilai variabel Learnability sebesar 80,74\% dinyatakan setuju, nilai variabel Memorability sebesar 95,6\% dinyatakan setuju, nilai variabel Efficiency sebesar 81,06\% dinyatakan setuju, nilai variabel Error sebesar 64\% dinyatakan kurang baik atau cukup dan nilai variabel Satisfaction sebesar 81,14\%. Dalam hal ini dapat disimpulkan bahwa usabilitas pada website SIKULI UMRI sudah baik, akan tetapi alangkah lebih baik pada website SIKULI UMRI dilakukan perbaikan terkait pada variabel Error agar website SIKULI UMRI dapat lebih baik dan nyaman saat digunakan.
\end{abstract}

Kata kunci: evaluasi, usabilitas, E-Learning, website, usability testing

\section{Evaluation of usability the umri e-learning website towards umri students using usability testing method}

\begin{abstract}
Website usability analysis can help evaluate website development. Through usability analysis can help improve the use of the system. Likewise on the UMRI e-learning website, usability analysis can provide input for SIKULI UMRI website developers. There are complaints from students that they cannot send assignments with a large number of files and there have been messages in the discussion column that have been sent repeatedly. In this case, the usability analysis aims to make the SIKULI UMRI website better when used by UMRI students. In this study using the Usability Testing method using 5 variables. The research was conducted by collecting data using an online questionnaire distributed to 99 UMRI students. Processing of questionnaire data using the Minitab application. This study found that the SIKULI UMRI website had a Learnability variable value of $80.74 \%$ agreed, the Memorability variable value was $95.6 \%$ agreed, the Efficiency variable value was $81.06 \%$ agreed, the Error variable value was $64 \%$ declared unfavorable. or sufficient and the value of the Satisfaction variable is $81.14 \%$. In this case, it can be concluded that the usability of the SIKULI UMRI website is good, but it would be better on the SIKULI UMRI website to make improvements related to the Error variable so that the SIKULI UMRI website can be better and more comfortable when used.
\end{abstract}

Keywords: evaluation, usability, E-Learning, website, usability testing

\section{Pendahuluan}

Penerapan teknologi informasi menjadikan proses penyebaran informasi dan komunikasi menjadi lebih cepat, mudah, dan tanpa batasan waktu. Karena adanya perkembangan teknologi informasi dan komunikasi tercipta suatu jaringan antar komputer yang saling berkaitan yang disebut website [32]. Website adalah situs yang berbasis teknologi web agar memungkinkan penggunanya mendapatkan informasi dari berselancar atau browsing. Dengan adanya hal ini pengguna komputer yang terhubung dengan internet akan mendapatkan informasi dengan cara mengunjungi website - website yang sudah tersebar di dunia maya [26]. Salah satu informasi yang ada pada situs website yaitu E-Learning. E-Learning adalah konsep dan mekanisme belajar mengajar 
(pendidikan) berbasis teknologi informasi transformasi pendidikan. E-learning merupakan model pembelajaran yang memanfaatkan fasilitas teknologi informasi dan komunikasi [12].

Universitas Muhammadiyah Riau membuat website E-Learning yaitu sistem informasi perkuliahan online Universitas Muhammadiyah Riau atau disingkat dengan nama SIKULI UMRI. SIKULI UMRI adalah website yang dibuat bertujuan untuk memudahkan mahasiswa dalam menerima informasi perkuliahan secara online yang sedang dijalani. Website SIKULI UMRI tentunya harus mempunyai kualitas usabilitas yang baik untuk menyajikan informasi perkuliahannya. Usabilitas mengacu kepada bagaimana pengguna bisa mempelajari dan menggunakan website untuk memperoleh tujuannya dan seberapa puas pengguna dalam menggunakan website tersebut [8]. Akan tetapi pada website SIKULI UMRI belum pernah dilakukannya evaluasi terhadap usabilitas pada websitenya dan adanya keluhan dari mahasiswa antara lain yaitu pada fitur kirim tugas bahwa fitur tersebut tidak dapat berfungsi dengan baik untuk mengirim file tugas dengan jumlah yang banyak hal tersebut membuat mahasiswa menjadi sulit untuk mengirim tugas dengan jumlah file yang banyak, lalu saat melakukan percakapan pada kolom diskusi pernah terjadinya pengiriman teks yang bertumpuk - tumpuk dalam satu kali pengiriman pesan. Dalam hal ini bagaimana penilaian mahasiswa terhadap usabilitas pada website SIKULI UMRI tersebut, tentunya kenyamanan dan kepuasan mahasiswa harus terus ditingkatkan guna mendukung kemajuan website SIKULI UMRI. Evaluasi usabilitas perlu dilakukan pada website SIKULI UMRI untuk memastikan bahwa website SIKULI UMRI dapat bekerja dengan benar dan sesuai dengan keinginan mahasiswa ketika menggunakannya. Usability Testing adalah salah satu cara metode yang dapat digunakan untuk mengevaluasi usabilitas pada suatu website.

Penelitian dilakukan pada website SIKULI UMRI dengan tujuan untuk mengetahui usabilitas pada website SIKULI UMRI terhadap mahasiswa. Penelitian ini dilakukan untuk menganalisa usabilitas website SIKULI UMRI terkait dengan Learnability, Memorability, Efficiency, Error dan Satisfaction sehingga, bisa menjadi rekomendasi atau masukkan bagi pihak pengembang website untuk perbaikan dan pengembangan website SIKULI UMRI yang bertujuan meningkatkan kualitas websitenya.

\section{Usabilitas}

Usabilitas berasal dari kata usable yang diartikan sebagai dapat digunakan dengan baik. Usabilitas didefinisikan sebagai tingkat sejauh mana produk yang digunakan oleh suatu kelompok pengguna tertentu dapat mencapai tujuan berdasarkan efisiensi, efektifitas, kepuasan [8]. Usabilitas merupakan nilai guna suatu produk, semakin tinggi nilai usabilitas suatu aplikasi, maka semakin mudah dan nyaman pula aplikasi digunakan. Antarmuka yang baik adalah mudah dipelajari (learnability), efisien (efficiency), mudah diingat (memorability), tingkat kesalahan dapat diatasi atau aman (errors), dan memiliki tingkat kepuasan (satisfication) [22].

\section{Usability Testing}

Usability Testing perlu dilakukan untuk mengetahui lebih dulu kemungkinan kendala penggunaan aplikasi yang akan dihadapi oleh pengguna. Penggunaan perangkat lunak ini bekaitan dengan nilai pengalaman yang dilalui oleh pengguna ketika proses pemakaian, perangkat yang digunakan dapat berupa perangkat dengan basis website, desktop ataupun mobile [6]. Usability Testing adalah tes kebergunaan suatu website, dimana metode ini dianggap objektif dan efektif untuk mengetahui tingkat kebergunaan website, dalam metode Usability Testing memiliki 5 variabel yaitu Learnability, Memorability, Efficiency, Error dan Satisfaction [28].

1. Learnability yaitu seberapa mudah pengguna memahami sistem [27].

2. Memorability yaitu tingkat ingatan pengguna dalam menggunakan sistem mengingat letak fitur dan tampilan sistem tersebut [9].

3. Efficiency yaitu sistem dapat menyelesaikan tugas - tugas tertentu dan sesuai dengan hasil yang diinginkan [11].

4. Error yaitu kegagalan fitur yang ditemukan pada sistem [1].

5. Satisfaction yaitu kepuasan pengguna terhadap penggunaan sistem [33].

\section{Website}

Website yaitu kumpulan halaman web yang dipublikasikan di internet yang dapat diakses pengguna internet dengan cara mengetikan alamatnya [17]. Website adalah situs yang berbasis teknologi web agar memungkinkan penggunanya mendapatkan informasi dari berselancar atau browsing. Dengan adanya hal ini pengguna komputer yang terhubung dengan internet akan mendapatkan informasi dengan cara mengunjungi website - website yang sudah tersebar di dunia maya [26]. Website yaitu halaman web yang berisi informasi dalam bentuk digital yang disediakan melalui jalur koneksi internet [13].

\section{E-Learning}

Pendidikan berbasis web, pembelajaran digital, pembelajaran interaktif, dengan bantuan komputer pengajaran dan pembelajaran berbasis internet yang dikenal sebagai E-learning. Hal ini terutama sistem pendidikan berbasis web yang menyediakan peserta didik dengan informasi atau keahlian memanfaatkan teknologi, karena e-learning, orang - orang dapat menghemat waktu dan 
tenaga [15]. E-Learning yaitu sistem yang ada di lembaga pendidikan konvensional yang di transformasikan kedalam sebuah sistem digital melalui internet [19].

\section{Evaluasi}

Evaluasi adalah suatu prosedur yang digunakan untuk mengukur sesuatu dengan aturan - aturan yang sudah ditentukan. Evaluasi program merupakan suatu proses yang mengacu pada pencapaian tujuan [2]. Evaluasi yaitu kegiatan untuk mengetahui keadaan objek menggunakan instrumen dan hasilnya dibandingkan dengan tolak ukur untuk kesimpulan [5].

\section{Rumusan Masalah}

Rumusan masalah sebagai berikut:

1. Seberapa besar tingkat usabilitas website SIKULI UMRI menggunakan metode Usability Testing terkait dengan variabel Learnability, Memorability, Efficiency, Error dan Satisfaction?

2. Indikator usabilitas website SIKULI UMRI mana saja yang sudah sesuai dengan keinginan mahasiswa dan yang memerlukan perbaikan?

\section{Tujuan}

Tujuan penelitian sebagai berikut:

1. Mengetahui seberapa besar tingkat usabilitas website SIKULI UMRI menggunakan metode Usability Testing terkait dengan Learnability, Memorability, Efficiency, Error dan Satisfaction.

2. Mengetahui indikator usabilitas website SIKULI UMRI yang sudah sesuai dengan keinginan mahasiswa dan yang memerlukan perbaikan.

\section{Kerangka Pikir}

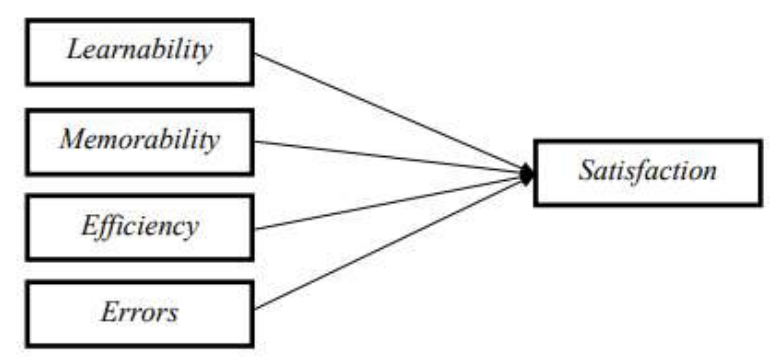

Gambar 1 Model Usability (Nulngafan and Sibyan, 2020).

Model diatas menunjukkan bahwa persepsi (Learnability) kemudahan dalam mempelajari sistem sehingga pengguna dapat dengan mudah menggunakannya mempengaruhi (Satisfaction) kepuasan pengguna, persepsi (Memorability) daya ingat pengguna untuk dapat dengan mudah mengingat cara penggunaan sistem mempengaruhi (Satisfaction) kepuasan pengguna, persepsi (Efficiency) sistem yang digunakan dapat menyelesaikan tugas secara akurat untuk mencapai tujuan pengguna mempengaruhi (Satisfaction) kepuasan pengguna, persepsi (Error) tingkat kesalahan sistem harus minimal sehingga pengguna membuat paling sedikit jumlah kesalahan saat menggunakan sistem mempengaruhi (Satisfaction) kepuasan pengguna. Pada penelitian ini yang merupakan parameter usabilitas website SIKULI UMRI adalah (Satisfaction) sistem harus memberikan kenyamanan dan juga memberikan sikap positif kepada pengguna [3].

\section{Hipotesis Penelitian}

Hipotesis bersumber dari [18].

1. Learnability berpengaruh positif terhadap Satisfaction.

2. Memorability berpengaruh positif terhadap Satisfaction.

3. Efficiency berpengaruh positif terhadap Satisfaction.

4. Errors berpengaruh positif terhadap Satisfaction.

5. Learnability, Memorability, Efficiency, Errors secara bersamaan berpengaruh positif terhadap Satisfaction. 


\section{Metode Penelitian}

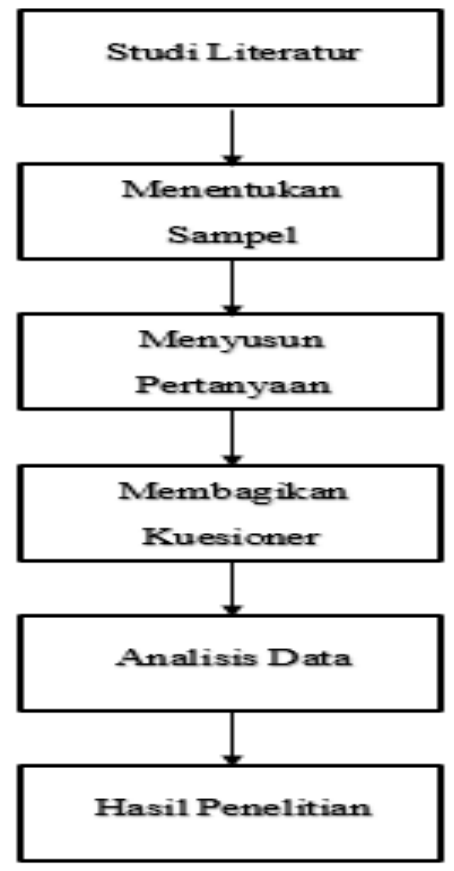

Gambar 2 Alur Penelitian

\subsection{Pengumpulan Data}

Populasi adalah wilayah generalisasi yang ditetapkan oleh penelitian untuk dipelajari dan kemudian ditarik kesimpulan dan sampel adalah bagian dari jumlah dan karakteristik populasi [14]. Apabila subjeknya lebih dari 100 orang, maka dapat diambil antara 10-15\% dari jumlah populasinya [25]. Usulan aturan praktis yang harus diikuti saat menentukan ukuran sampel, yaitu jumlah partisipan dalam kuesioner minimal 30 orang untuk memperoleh hasil yang baik [21].

Penelitian ini yaitu penelitian kuantitatif dengan kuesioner online untuk pengumpulan datanya. Dengan demikian kuesioner disiapkan oleh peneliti dimana tiap pertanyaannya berkaitan dengan masalah penelitian. Kuesioner disebarkan kepada mahasiswa Universitas Muhammadiyah Riau sebagai respondennya. Skala Likert adalah metode pengukuran suatu kualitas untuk mengetahui nilai kualitas tersebut [20].

Tabel 1 Skala Likert

\begin{tabular}{|c|c|c|}
\hline No & Jawaban & Skala Likert \\
\hline 1 & Sangat tidak setuju (STS) & 1 \\
\hline 2 & Tidak setuju (TS) & 2 \\
\hline 3 & Kurang Setuju (KS) & 3 \\
\hline 4 & Setuju (S) & 4 \\
\hline 5 & Sangat setuju (SS) & 5 \\
\hline
\end{tabular}

Penelitian ini sampel berasal dari mahasiswa UMRI yang aktif saat ini berjumlah keseluruhan (populasi) 6623 mahasiswa dan dilakukan pengambilan sampel menggunakan rumus Slovin dengan error tolerance $10 \%$. Jumlah sampel yang ditetapkan adalah 99 responden. Digunakan metode Simple Random Sampling sehingga sampel dipilih secara acak [30]. Pemilihan respondennya dilakukan secara acak sesuai dengan jumlah sampel yang ditargetkan [4].

\subsection{Variabel Penelitian}

Penelitian ini menggunakan 5 variabel dan terbagi menjadi dua jenis variabel yaitu:

1. Variabel independen yang digunakan dalam penelitian ada empat variabel adalah variabel Learnability $(X 1)$, variabel Memorability(X2), variabel Efficiency $(X 3)$ dan variabel Error(X4).

2. Variabel dependen yang digunakan dalam penelitian adalah variabel $\operatorname{Satisfaction}(Y)$.

\subsection{Instrumen Penelitian}


Kuesioner merupakan alat pengumpulan data untuk memperoleh opini responden [31]. Dalam menyusun pertanyaan terkait usabilitas website SIKULI UMRI, kuesioner terbagi menjadi 5 variabel pertanyaan berdasarkan referensi [29].

Tabel 2 Pertanyaan Pertanyaan Usabilitas Website SIKULI UMRI

\begin{tabular}{|c|c|}
\hline & Pertanyaan Usabilitas Website SIKULI UMRI \\
\hline \multirow[t]{3}{*}{ Learnability } & (A1) Website SIKULI UMRI dapat dipelajari dengan mudah? \\
\hline & $\begin{array}{l}\text { (A2) Saya dengan mudah dan cepat menerima informasi secara detail dan juga } \\
\text { spesifik pada Website SIKULI UMRI? }\end{array}$ \\
\hline & $\begin{array}{l}\text { (A3) Saya mampu dengan mudah memahami dan mengerti alur dari navigasi yang } \\
\text { ada pada Website SIKULI UMRI? }\end{array}$ \\
\hline \multirow[t]{3}{*}{ Memorability } & (B1) Saya dapat dengan mudah mengingat penggunaan Website SIKULI UMRI? \\
\hline & $\begin{array}{l}\text { (B2) Saya dapat dengan mudah mengetahui dan mengingat arah navigasi dan fitur } \\
\text { pada Website SIKULI UMRI? }\end{array}$ \\
\hline & (B3) Saya merasa mudah kapanpun menggunakan Website SIKULI UMRI? \\
\hline \multirow[t]{3}{*}{ Efficiency } & $\begin{array}{l}\text { (C1) Saya mampu melakukan akses menu pada Website SIKULI UMRI dengan } \\
\text { cepat? }\end{array}$ \\
\hline & $\begin{array}{l}\text { (C2) Saya dengan mudahnya memperoleh informasi yang ada terkait Website } \\
\text { SIKULI UMRI? }\end{array}$ \\
\hline & $\begin{array}{l}\text { (C3) Saya mampu langsung menemukan informasi yang saya ingin cari dari awal } \\
\text { membuka pada Website SIKULI UMRI? }\end{array}$ \\
\hline \multirow[t]{3}{*}{ Error } & (D1) Saya tidak menemukan error disaat menggunakan Website SIKULI UMRI? \\
\hline & $\begin{array}{l}\text { (D2) Saya tidak menemukan menu yang error atau tidak sesuai dengan fungsinya } \\
\text { pada Website SIKULI UMRI? }\end{array}$ \\
\hline & $\begin{array}{l}\text { (D3) Saya dapat menemukan fitur dan menu yang saya cari pada Website SIKULI } \\
\text { UMRI? }\end{array}$ \\
\hline \multirow[t]{3}{*}{ Satisfaction } & $\begin{array}{l}\text { (E1) Saya senang dengan desain antarmuka yang ada pada Website SIKULI UMRI } \\
\text { secara keseluruhan? }\end{array}$ \\
\hline & (E2) Saya merasa nyaman dalam menggunakan Website SIKULI UMRI? \\
\hline & $\begin{array}{l}\text { (E3) Paduan warna dan tata letak konten pada Website SIKULI UMRI nyaman } \\
\text { untuk dilihat? }\end{array}$ \\
\hline
\end{tabular}

\subsection{Pengolahan Data}

Pengolahan data yang akan dilakukan adalah mencari nilai mean pada variabel kemudian melakukan pengujian instrumen dan analisis data menggunakan aplikasi Minitab. Minitab merupakan aplikasi statistika yang digunakan untuk pengolahan data statistik [34]. Berdasarkan item setiap instrumen pertanyaan dan total statistik untuk mengetahui nilai mean, maka diperoleh data sebagai berikut:

\begin{tabular}{ccc}
\multicolumn{3}{c}{ Tabel 3 Mean } \\
\hline Variabel & $\begin{array}{c}\text { Total } \\
\text { Count }\end{array}$ & Mean \\
\hline Learnability(A1) & 99 & 4,182 \\
\hline Learnability(A2) & 99 & 3,960 \\
\hline Learnability(A3) & 99 & 3,970 \\
\hline Memorability(B1) & 99 & 4,172 \\
\hline Memorability(B2) & 99 & 3,929 \\
\hline Memorability(B3) & 99 & 4,131 \\
\hline Efficiency(C1) & 99 & 4,121 \\
\hline Efficiency(C2) & 99 & 4,121 \\
\hline Efficiency(C3) & 99 & 3,919 \\
\hline Error(D1) & 99 & 2,970 \\
\hline Error(D2) & 99 & 3,030 \\
\hline Error(D3) & 99 & 3,596 \\
\hline
\end{tabular}




\begin{tabular}{lcc}
\hline Satisfaction(E1) & 99 & 4,061 \\
\hline Satisfaction(E2) & 99 & 3,889 \\
\hline Satisfaction(E3) & 99 & 4,222
\end{tabular}

Nilai total mean:

1. Variabel Learnability 4,037 dinyatakan setuju.

2. Variabel Memorability 4,780 dinyatakan setuju.

3. Variabel Efficiency 4,053 dinyatakan setuju.

4. Variabel Error 3.200 dinyatakan kurang setuju atau cukup.

5. Variabel Satisfaction 4,057 dinyatakan setuju.

\subsection{Pengujian Instrumen}

Uji Validitas digunakan untuk mengukur valid tidaknya suatu kuesioner. Sig 0,05 nilai r hitung > r tabel [10]. Disimpulkan bahwa butir instrumen tersebut valid.

\begin{tabular}{|c|c|c|c|}
\hline \multicolumn{4}{|c|}{ el 4 Uji Validitas } \\
\hline Instrumen & $\mathbf{N}$ & r hitung & $r$ tabel \\
\hline Learnability(A1) & 99 & 0,594 & 0,1975 \\
\hline Learnability(A2) & 99 & 0,639 & 0,1975 \\
\hline Learnability(A3) & 99 & 0,710 & 0,1975 \\
\hline Memorability(B1) & 99 & 0,589 & 0,1975 \\
\hline Memorability(B2) & 99 & 0,731 & 0,1975 \\
\hline Memorability(B3) & 99 & 0,667 & 0,1975 \\
\hline Efficiency $(\mathrm{C} 1)$ & 99 & 0,469 & 0,1975 \\
\hline Efficiency(C2) & 99 & 0,595 & 0,1975 \\
\hline Efficiency(C3) & 99 & 0,682 & 0,1975 \\
\hline Error(D1) & 99 & 0,612 & 0,1975 \\
\hline Error(D2) & 99 & 0,576 & 0,1975 \\
\hline Error(D3) & 99 & 0,671 & 0,1975 \\
\hline Satisfaction(E1) & 99 & 0,503 & 0,1975 \\
\hline Satisfaction(E2) & 99 & 0,776 & 0,1975 \\
\hline Satisfaction(E3) & 99 & 0,606 & 0,1975 \\
\hline
\end{tabular}

Uji Reliabilitas diuji menggunakan Alpha Cronbach, nilai Alpha Cronbach reliabel jika nilai Alpha $\geq 0,6$ [23]. Disimpulkan bahwa variabel tersebut reliabel.

\begin{tabular}{c|c}
\multicolumn{2}{c}{ Tabel 5 Uji Reliabilitas } \\
\hline Variable & $\begin{array}{c}\text { Cronbach's } \\
\text { Alpha }\end{array}$ \\
\hline Learnability(X1) & 0,7811 \\
\hline Memorability(X2) & 0,7664 \\
\hline Efficiency(X3) & 0,7965 \\
\hline Error(X4) & 0,8109 \\
\hline Satisfaction(Y) & 0,7698 \\
\hline
\end{tabular}

\subsection{Analisis Data}

Regresi Linier Berganda adalah pengaruh variabel independen (variabel bebas) terhadap variabel dependen (terikat) [10]. 


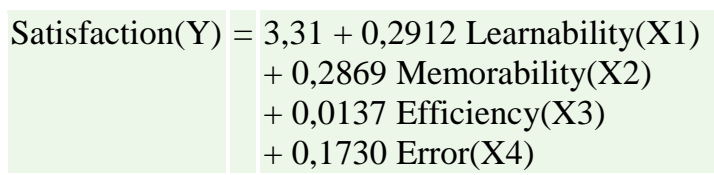

Uji Normalitas menggunakan uji Kolmogorov - Smirnov. Nilai signifikan > 0,05 [16]. Bahwa hasil pengujian normalitas nilai uji sebesar > 0,150. Disimpulkan bahwa data berdistribusi normal. Uji Multikolinearitas regersi yang baik tidak terjadi kolerasi diantara variabel independen nilai $V I F<10$ [16]. Disimpulkan bahwa uji dinyatakan valid.

\begin{tabular}{c|c}
\multicolumn{2}{c}{ Tabel 6 Uji Multikolinearitas } \\
\hline Term & VIF \\
\hline Learnability(X1) & 1,59 \\
\hline Memorability(X2) & 1,77 \\
\hline Efficiency(X3) & 1,53 \\
\hline Error(X4) & 1,40
\end{tabular}

Uji Autokorelasi regresi yang baik mensyaratkan tidak adanya masalah autokorelasi dU < DW < 4-dU [7]. Maka dapat disimpulkan nilai dU $<\mathrm{DW}<4-\mathrm{dU}(1,7575<1,80262<2,2425)$ uji dinyatakan valid. Uji Heteroskedastisitas untuk mengetahui apakah sebuah model regresi terjadi ketidaksamaan varian residual melihat grafik Scatterplot. Hasil yang baik menunjukkan bahwa titik - titik data menyebar di sekitar angka 0 dan titik - titik tersebut tidak mengumpul hanya diatas ataupun dibawah saja [24]. Disimpulkan bahwa uji dinyatakan valid.

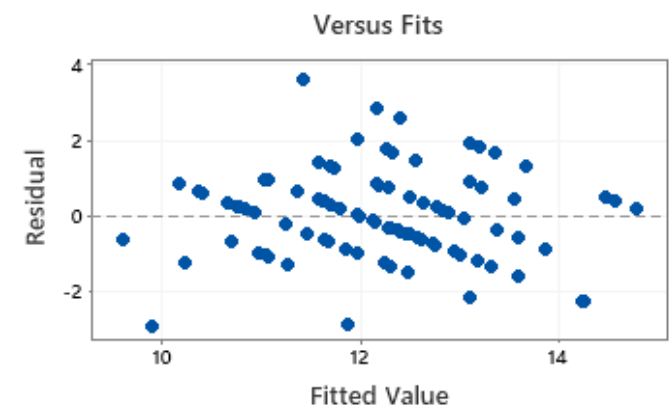

Gambar 3 Grafik Scatterplot Uji Heteroskedastisitas

Uji Hipotesis dengan cara uji t, uji t pada probabilitas value yang dinyatakan berpengaruh adalah $(\alpha) \leq 0,05[10]$.

\begin{tabular}{ccc} 
& Tabel 7 Uji Hipotesis & \\
\hline Source & P-Value & Hasil \\
Regression & 0,000 & Tolak HO Terima Ha \\
Leamability $(X 1)$ & 0,001 & Tolak HO Terima Ha \\
\hline Memorability $(X 2)$ & 0,002 & Tolak HO Terima Ha \\
Efficiency $(X 3)$ & 0,882 & Talak Ha Terima HO \\
Elror $(X 4)$ & 0,011 & Tolak HO Terima Ha \\
\hline
\end{tabular}

1. Hipotesis Learnability berpengaruh signifikan terhadap Satisfaction.

2. Hipotesis Memorability berpengaruh signifikan terhadap Satisfaction.

3. Hipotesis Efficiency tidak berpengaruh signifikan terhadap Satisfaction.

4. Hipotesis Error berpengaruh signifikan terhadap Satisfaction.

5. Secara simultan regression hipotesis Learnability, Memorability, Efficiency, Error secara bersamaan berpengaruh signifikan terhadap Satisfaction.

\section{HASil dan PEMbahasan}

Berdasarkan tingkat usabilitas website SIKULI UMRI terhadap mahasiswa Universitas Muhammadiyah Riau menggunakan pengukuran Skala Likert, maka diperoleh data sebagai berikut: 


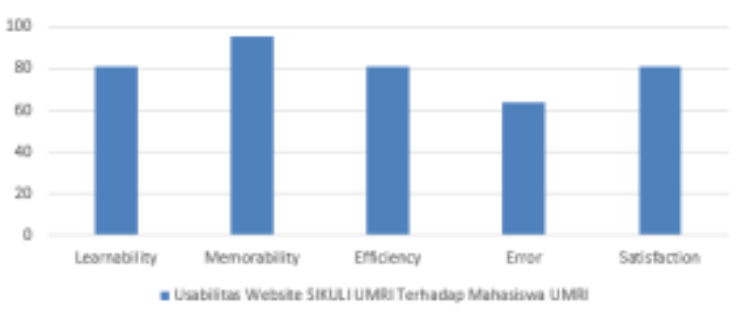

Gambar 4 Tingkat Usabilitas Website SIKULI UMRI

Nilai total tingkat usabilitas pada variabel Learnability dengan mean sebesar $4,037=80,74 \%$ dinyatakan setuju, nilai total tingakat usabilitas pada variabel Memorability dengan mean sebesar 4,780 $=95,6 \%$ dinyatakan setuju, nilai total tingkat usabilitas pada variabel Efficiency dengan mean sebesar 4,053 = 81,06\% dinyatakan setuju, nilai total tingkat usabilitas pada variabel Error dengan mean sebesar 3.200 =64\% dinyatakan kurang setuju atau cukup, nilai total tingkat usabilitas pada variabel Satisfaction dengan mean sebesar 4,057 $=81,14 \%$ dinyatakan setuju.

\section{KESIMPULAN}

Penilaian tingkat usabilitas website SIKULI UMRI terhadap mahasiswa Universitas Muhammadiyah Riau yaitu:

1. Pada variabel Learnability usabilitas website SIKULI UMRI yaitu mean sebesar $4,037=80,74 \%$.

2. Pada variabel Memorability usabilitas website SIKULI UMRI yaitu mean sebesar 4,780 =95,6\%.

3. Pada variabel Efficiency usabilitas website SIKULI UMRI yaitu mean sebesar $4,053=81,06 \%$.

4. Pada variabel Error usabilitas website SIKULI UMRI yaitu mean sebesar $3.200=64 \%$.

5. Pada variabel Satisfaction usabilitas website SIKULI UMRI yaitu mean sebesar 4,057 =81,14\%.

Penjelasan indikator usabilitas website SIKULI UMRI yang sudah sesuai dengan keinginan mahasiswa dan yang memerlukan perbaikan yaitu:

1. Learnability pada website SIKULI UMRI yaitu sebesar 80,74\% dikatakan setuju, hipotesis Learnability dinyatakan berpengaruh signifikan terhadap Satisfaction usabilitas website SIKULI UMRI.

2. Memorability pada website SIKULI UMRI yaitu sebesar 95,6\% dikatakan setuju, hipotesis Memorability dinyatakan berpengaruh signifikan terhadap Satisfaction usabilitas website SIKULI UMRI.

3. Efficiency pada website SIKULI UMRI yaitu sebesar $81,06 \%$ dikatakan setuju, hipotesis Efficiency dinyatakan tidak berpengaruh signifikan terhadap Satisfaction usabilitas website SIKULI UMRI.

4. Error pada website SIKULI UMRI yaitu sebesar 64\% dikatakan kurang setuju atau cukup, hipotesis Error dinyatakan berpengaruh signifikan terhadap Satisfaction usabilitas website SIKULI UMRI.

Satisfaction pada website SIKULI UMRI yaitu sebesar 81,14\% dikatakan setuju, secara simultan hipotesis regresi Learnability, Memorability, Efficiency dan Error dinyatakan berpengaruh signifikan terhadap Satisfaction usabilitas website SIKULI UMRI.

\section{Daftar Pustaka}

[1] Adnan, F., Prasetyo, B. and Nuriman, N. (2017) 'Usability testing analysis on the Bana game as education game design references on junior high school', Jurnal Pendidikan IPA Indonesia, 6(1), pp. 88-94. doi: 10.15294/jpii.v6i1.9597.

[2] Agustanico Dwi Muryadi (2017) 'Model Evaluasi Program Dalam Penelitian Evaluasi’, Jurnal Ilmiah PENJAS, 3(1), pp. 1-14.

[3] Alturki, R. and Gay, V. (2017) 'Usability Testing of Fitness Mobile Application : Methodology and Quantitative Results', Computer Science \& Information Technology (CS \& IT), pp. 97-114. doi: 10.5121/csit.2017.71108.

[4] Arieska, P. K. dan N. H. (2018) 'Pemilihan Teknik Sampling Berdasarkan Perhitungan Efisiensi Relatif', Jurnal Statistika, 6(2), pp. 166-171.

[5] B., M. (2017) 'Evaluasi Belajar Peserta Didik (SISWA)', Jurnal Idaarah, 1(2), pp. 257-267.

[6] Dananjaya, W. P. et al. (2020) 'E-Learning Pinandita Berbasis Website Studi Kasus Pasraman Brahma Vidya Samgraha Buleleng', Jurnal Ilmiah Merpati, $8(2)$, pp. 146-155.

[7] Didin, I. (2018) 'Pengaruh stabilitas keuangan, kondisi industri dan tekanan eksternal terhadap kecurangan laporan keuangan', Jurnal Kajian Akuntansi, 2(1), pp. 82-97.

[8] Dinda, M. (2020) ‘Analisis Usabilitas Pada Situs Berita Dengan Metode Usability Testing’, Prosiding IENACO, p. 359.

[9] Gupta, D., Ahlawat, A. K. and Sagar, K. (2017) 'Usability Prediction \& Ranking of SDLC Models Using Fuzzy Hierarchical Usability Model', Open Engineering, 7(1), pp. 161-168. doi: 10.1515/eng-2017-0021.

[10] Hendri and Setiawan, R. (2017) 'Pengaruh motivasi kerja dan kompensasi terhadap kinerja karyawan di PT. Samudra Bahari Utama', Jurnal AGORA, 5(1), pp. $1-8$.

[11] Huda, N. (2019) 'Implementasi Metode Usability Testing Dengan System Usability Scale Dalam Penilaian Website Rs Siloam Palembang', Klik - Kumpulan Jurnal Ilmu Komputer, 6(1), p. 36. doi: 10.20527/klik.v6i1.177.

[12] Jimi, A. (2020) 'Perancangan Sistem E-Learning Berbasis Web Pada Smp N 2 Busalangga', Jurnal Pendidikan Teknologi Informasi (JUKANTI), 3(1), pp. 29-37. doi: 10.37792/jukanti.v3i1.108.

[13] Josi, A. (2017) 'Penerapan Metode Prototyping Dalam Membangun Website Desa (Studi Kasus Desa Sugihan Kecamatan Rambang)', Jti, 9(1), pp. 50-57.

[14] Komala, R. D. (2017) 'Jurnal Fakultas Ilmu Terapan Universitas Telkom', Jurnal Fakultas Ilmu Terapan Universitas Telkom, 3(2), pp. 330-337.

[15] Maatuk, A. M. et al. (2021) 'The COVID-19 pandemic and E-learning: challenges and opportunities from the perspective of students and instructors', Journal of Computing in Higher Education, (0123456789). doi: 10.1007/s12528-021-09274-2.

[16] Nanicova, N. (2019) 'Pengaruh Kualitas Layanan Terhadap Kepuasan Pelanggan Noach Cafe And Bistro', Agora, 7(2). 
[17] Nofyat, Ibrahim, A. and Ambarita, A. (2018) 'Sistem Informasi Pengaduan Pelanggan Air Berbasis Website Pada Pdam Kota Ternate', IJIS - Indonesian Journal On Information System, 3(1). doi: 10.36549/ijis.v3i1.37.

[18] Nulngafan, N. and Sibyan, H. (2020) 'Analisis Faktor-Faktor Usability pada Website RSUD Wonosobo', Journal of Economic, Management, Accounting and Technology, 3(1), pp. 49-54. doi: 10.32500/jematech.v3i1.1080.

[19] Nuryadi, N. (2018) 'Rancang Bangun Aplikasi Website E-Learning Pada Smk Respati 1 Jakarta', 4(1).

[20] Pranatawijaya, V. H. et al. (2019) 'Penerapan Skala Likert dan Skala Dikotomi Pada Kuesioner Online', Jurnal Sains dan Informatika, 5(2), pp. 128-137. doi: $10.34128 /$ jsi.v5i2.185.

[21] Prasetyo, M. A., Musta, M. and Ikhwani, H. (2020) 'Pemberdayaan Potensi Wisata Pantai Kenjeran Surabaya', Jurnal Teknik ITS, 9(2), pp. $2-7$.

[22] Pratiwi, K. Y. and Suprihatin, S. (2019) 'Analisis Usability Sistem Informasi Layanan Mandiri Di Perpustakaan Universitas Brawijaya', Jurnal Pustaka Ilmiah, 5(2), p. 931. doi: 10.20961/jpi.v5i2.37880.

[23] Rahayu, S. and Rahmawati, T. (2019) 'Uji Validitas dan Reliabilitas Kuesioner Kebutuhan Informasi Caregivers Keluarga (K-KICK)', Dinamika Kesehatan Jurnal Kebidanan Dan Keperawatan, 10(2), pp. 838-846. doi: 10.33859/dksm.v10i2.513.

[24] Saragi Sitio, V. S. (2018) 'Pengaruh Total Quality Management (Tqm) Dan Gaya Kepemimpinan Terhadap Kinerja Karyawan Pada Pt. Pelita Air Service', Journal of Management and Business Review, 15(2), pp. 196-218. doi: 10.34149/jmbr.v15i2.128.

[25] Sari, R. F. (2017) 'Hubungan Pengetahuan Guru Tentang Manajemen Pembelajaran dengan Kinerja Guru di MTs Negri 2 Medan', Jurnal Manajemen Pendidikan Islam, 1(1), pp. 1-11.

[26] Setiawan, A. and Widyanto, R. A. (2018) 'Evaluasi Website Perguruan Tinggi menggunakan Metode Usability Testing', Jurnal Informatika: Jurnal Pengembangan IT, 3(3), pp. 295-299. doi: 10.30591/jpit.v3i3.912.

[27] Subiyakto, A. and Wijaya, D. J. (2018) 'Evaluasi Website Badan Pusat Stastistik Menggunakan Metode Usability Testing', Applied Information System and Management (AISM), 1(2), pp. 81-89. doi: 10.15408/aism.v1i2.20103.

[28] Suharyanto (2019) 'Evaluasi User Interface Website Universitas Respati Indonesia Menggunakan Metode Usability Testing', Jurnal Teknologi Informasi ESIT, 16(03), pp. 6-10.

[29] Sukmasetya, P., Setiawan, A. and Arumi, E. R. (2020) 'Penggunaan Usability Testing Sebagai Alat Evaluasi', 9(1), pp. 58-67.

[30] Taherdoost, H. (2018) 'Sampling Methods in Research Methodology; How to Choose a Sampling Technique for Research', SSRN Electronic Journal, (January 2016). doi: 10.2139/ssrn.3205035.

[31] Wahyu Wijaya, I. N. S. and Atmaja, K. J. (2019) 'Pengembangan Sistem Evaluasi Kinerja Dosen (E-Kuesioner) Stmik Stikom Indonesia’, JST (Jurnal Sains dan Teknologi), 8(1), p. 55. doi: 10.23887/jst-undiksha.v8i1.17290.

[32] Yul, F. A. and Jannah, M. (2020) 'Analisis Usabilitas Website Siam Umri Menggunakan Metode Usability Testing', Jurnal Surya Teknika, 7(1), pp. 8695. doi: 10.37859/jst.v7i1.2355.

[33] Yuniarto, D. et al. (2019) 'Integrating the Readiness and Usability Models for Assessing the Information System Use', 2018 6th International Conference on Cyber and IT Service Management, CITSM 2018, (Citsm), pp. 5-10. doi: 10.1109/CITSM.2018.8674349.

[34] Zulhelmi, Adlim and Mahidin (2017) 'Pengaruh Media Pembelajaran Interaktif Terhadap', Jurnal Pendidikan Sains Indonesia, 05(01), pp. 72-80. 